\title{
Why study Global Health?
}

\section{Amatya A, Basel P}

Department of Community Medicine and Public Health Institute of Medicine

Kathmandu, Nepal

Is it imperative to know what happens to the health of other people especially of other people in another country? Why is it important to know the health status of those who live in Australia, Germany, the United States or any other developed country for that accord? However if you look at it from a broader perspective it matters a lot and a growing concern for many of us.

Foremost of all, diseases have no boundaries. ${ }^{1}$ For example if someone has tuberculosis he/she can spread it to many during his/her lifetime, wherever he/she resides or travel to. In other words the health of each of us directly and indirectly affects others as well. It would be erroneous to say that in a way health is not related to the economic and social development of a country and it is indeed closely related in many ways, in this increasingly growing independent world. There are many children and adolescents who do not complete their basic education due to their disease condition or due to malnutrition, which prevents them to their full mental potential which otherwise would have been possible. They would be less likely to be as productive when adults as other children form developed countries, and will be able to contribute less to their families, community and country.

It is also evident that an ethical dimension exists on the health and well being of other people. There are millions of elderly people who spend their lives in very poor conditions because of the lack of care by the state and strong policies to govern such issues and children still suffer and die of vaccine preventable diseases and malnutrition which can be both prevented and cured. Is this fair and justified? Are we prepared to accept suffering and deaths without taking steps to prevent them? Eventually if we look at health in a broader dimension, health and well being of people everywhere adds on to the freedom in the world. Outbreaks of disease like SARS (Severe Acute Respiratory Syndrome) and cholera, threaten us to work to the fullest and be involved in gainful quests.

However the last 50 years has shown great results in improving human health. Since 1950 s the death rate of under five children has fallen from 148 deaths per 1000 live births to 65 deaths per 100 live births. Despite incredible improvements in health since 1950, there are still a number of challenges ahead. ${ }^{2}$

A definitive working Definition of global health was proposed by Kaplan et al as "Global health is an area or study, research, practice that places a priority on improving health and achieving equity in health in all people worldwide. Global health emphasizes transnational health issues, determinants and solutions; involves many disciplines within and beyond the health sciences and promotes inter-disciplinary collaboration; and is a synthesis of population based prevention with individual level health care". ${ }^{3}$

Health situation is constantly in transition and more and more dependent on other parts of the world. In the context, of Nepal there has been a sharp decline of maternal deaths since 1996,immunization rates has gone up almost a double during the same period. ${ }^{4}$ Similarly very impressive health indicators can be seen for infant and child mortality. Nevertheless it is important to tie up with international partners to reach the global target. A good example is to take into account the good health indicators of Finland among the partnering organization. Local phenomenon cannot be explained without understanding the larger entity against one's own settings and comparing it with others at the same time.

\section{The Role of Student Researchers in Global Health Research}

It is important to take an interdisciplinary approach to global health problems, which are often multi-faceted in nature. Health is a broad concept; it is not simply a biological phenomenon but is also influenced by various social, economic and political determinants. Diseases, as much as they are caused by microorganisms, are also linked to certain "inherently global health issues,"

Due to the diverse determinants of health, there are many ways for students to be involved in global health research. Global health research is a collaborative process; each researcher contributes a piece to solving 
the puzzle of disease and morbidity. Multi-disciplinary research findings are used to tackle key health problems. Therefore, research must focus on concerns raised by developing countries, closing not only the gap in health disparities within countries, but also the gap in knowledge between the developed and developing world.

\section{Global Health Program}

Global Health Program's aim is to train medical doctors, dentists, veterinarians and students of these disciplines in global public health issues. The training is mainly done in annually organized four-week certificate courses. ${ }^{4}$ The Conceptual foundation of global health, social determinants of health, measuring health and disease and distribution of health and disease are the four primary modules shared and discussed under the Global health course. The Global Health Program conducted by Duodecim and University of Tampere is an international network of public health oriented organizations in Chile (Universidad de Chile), Finland, the Philippines (University of the Philippines), Nepal (Tribhuvan) and Tanzania (Muhimbili University of Health and Applied Sciences and Sokoine University of Agriculture).

Institute of Medicine (IOM) is proud to be the part of this global health community by organizing the diploma course in Nepal which was held from 5th to 30th August, 2013. ${ }^{7}$ More like the previous diploma courses, this course includes two and a half weeks of theoretical part and one and half weeks of practical part. The theoretical part was run by the highly skilled national and international professionals, on relevant topics, within the premises of National Center for Health Professions Education (NCHPE) within IOM. As a part of the practical part of the course, the participants, both national and international, were able to have experiences with the different health sector stakeholders including ministry of health and population, NGOs and INGOs of Nepal. There were 34 participants from different Global Health partner countries including Nepal, Finland, Chile, Tanzania, Philippines. The program was funded by DUODECIM, Finnish medical society and the course was certified by the University of Tampere, Finland. The academic course was fully run by Global Health Unit (GHU), Institute of Medicine. IOM will be conducting these courses in future with the objective of sharing knowledge and with the concept of bringing together participants from different countries to discuss issues of global health.

\section{REFERENCES}

1. Skolnik R. Global Health 101, $2^{\text {nd }}$ edition, 2012 Jones and Barlett Learning http://www.jbpub.com/essentialpublichealth/skolnik/2e/

2. Global health overview, available from www.globalissues.org /article/588/global-health-overview

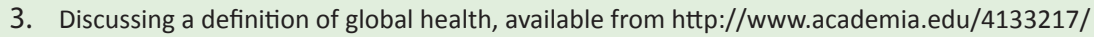

4. New ERA Kathmandu, Ministry of Health and Population Nepal, Nepal Demographic and Health Survey, 2011.

5. The Importance of Global Health Research: Closing The 10/90 Gap, available from http://www.uniteforsight.org/global-impact-lab/global-healthresearch

6. Duodecim-UTA Training programme on global health available from www.globalhealth.fi /program.html

7. Global health course, available at http://www.globalhealth.fi/Nepal_2013_Program.pdf 